This item was submitted to Loughborough's Research Repository by the author.

Items in Figshare are protected by copyright, with all rights reserved, unless otherwise indicated.

\title{
The use of holographic optical elements (HOE's) to investigate the use of a flat irradiance profile in the control of heat absorption in wire-fed laser cladding
}

\section{PLEASE CITE THE PUBLISHED VERSION}

http://dx.doi.org/10.1016/j.jmatprotec.2015.01.023

\section{PUBLISHER}

(C) Elsevier B.V.

\section{VERSION}

NA (Not Applicable or Unknown)

\section{PUBLISHER STATEMENT}

This work is made available according to the conditions of the Creative Commons Attribution-NonCommercialNoDerivatives 4.0 International (CC BY-NC-ND 4.0) licence. Full details of this licence are available at: https://creativecommons.org/licenses/by-nc-nd/4.0/

\section{LICENCE}

CC BY-NC-ND 4.0

\section{REPOSITORY RECORD}

Goffin, Nick, Rebecca Higginson, and John Tyrer. 2015. "The Use of Holographic Optical Elements (hoe's) to Investigate the Use of a Flat Irradiance Profile in the Control of Heat Absorption in Wire-fed Laser Cladding". Loughborough University. https://hdl.handle.net/2134/16809. 


\title{
The use of Holographic Optical Elements (HOE's) to investigate the use of
}

\section{a flat irradiance profile in the control of heat absorption in wire-fed laser}

\section{cladding}

\author{
N.J. Goffin ${ }^{a^{*}}$, R.L. Higginson ${ }^{\mathrm{b}}$, J.R. Tyrer ${ }^{\mathrm{a}}$
}

${ }^{a}$ Wolfson School of Mechanical and Manufacturing Engineering, Loughborough University, Loughborough, LE11 3TU

${ }^{b}$ Department of Materials, Loughborough University, Loughborough, LE11 3TU

\begin{abstract}
This work investigates the use of Holographic Optical Elements (HOE's) to control the applied heat profile and thermal absorption of a wire used for laser cladding. The two thermal distributions compared were a circular beam with a Gaussian heat profile (Gaussian beam) and a square beam with a flat profile (pedestal beam). Heat absorption calculations between these were carried out to show the potential differences in absorption, with empirical results created to show how the differences in absorption affect the cladding properties. Micrographs of the clad cross-sections were created using optical microscopy and were analysed with respect to wetting angle and clad dilution. These results were compared to an alternative method of applying an even beam profile; enlarging the Gaussian beam relative to the wire diameter. The results showed that the use of a HOE to create a more even beam profile gave superior wetting behaviour and less dilution.
\end{abstract}

Keywords: laser, cladding, wire, steel, absorption, reflectivity

* Corresponding Author, email address: n.goffin@lboro.ac.uk, Tel: +44 01509227594 


\section{Introduction}

Laser cladding is a material coating technique in which a laser is used to coat the surface of one material (the substrate) with a second material (the clad material). This has a range of applications; such as surface protection (Mahmood et al. 2012), component repair (Capello et al. 2005) and manufacturing (Miranda et al. 2008).

At present, the majority of effort is focussed on powder-based methods, either powder-bed systems, which the majority of commercial additive manufacturing processes use, or powder feeding systems such as the LENS ${ }^{\mathrm{TM}}$ and DMD (Direct Metal Deposition) systems (Mazumder et al. 2000).

Major disadvantages in wire feeding methods have limited its use as a manufacturing method by industry: Wire feeding is highly sensitive to changes in processing parameters (Toyserkani et al. 2005); clad tracks produced by wire feeding tend to have low surface quality, low bonding strength and a high incidence of porosity and cracking. Dilution is typically much higher for wire than it is for powder (Vilar 1999). In addition, the absorption coefficient for wire is lower than that for powder, making it comparatively inefficient; although research has found that this can be mitigated by pre-heating the wire (Liu et al. 2014).

Improvements to the above mean that wire feeding has considerable potential. A principle advantage of wire feeding is that it gives a much higher deposition rate than powder feeding (Syed et al. 2006), along with a far greater material efficiency; both of which are used by manufacturers interested in large-area deposition. Close to $100 \%$ of the material delivered is deposited, as opposed to $40 \%$ for powder (Syed et al. 2005), although the material cost of powder can be mitigated by increasing catchment efficiency (Riveiro et al. 2014). Wire is also far more suitable for automatic production, since it is easier to regulate the feeding of wire than the blowing of powder. It is much easier to adapt a wire feeder to awkward 
cladding positions, such as the inside of tubes (Kim \& Peng 2000), or other directions, such as overhead cladding.

The use of beam shaping techniques to alter the profile of the laser beam provides a possible method of achieving the required improvements to wire feeding:

1. Low surface quality is generally caused by inputting too much heat into the wire, whereas low bond strength is created when not enough heat is applied. Beam shaping allows heat input to be selectively altered, to increase it in areas with poor bond strength and reduce it in areas where too much heat is applied.

2. Porosity and cracking are products of stresses created by large thermal gradients. Thermal gradients are a feature of $\mathrm{TEM}_{00}$ Gaussian beams, so a way to mitigate this would be to alter the geometry of the incident beam.

3. Dilution can be controlled in a similar manner to Point 1 , by using beam shaping to selectively reduce the heating of high dilution areas and place extra heat where it is needed, in order to reduce overall dilution, while retaining high bond strength.

4. The lower absorption coefficient of wire can be compensated for by synchronising the beam shape with the wire absorption profile to tailor the wire absorption to the process requirements.

There are multiple methods for altering the energy distribution of a laser beam; for example: diode lasers, which can produce a rectangular beam with a flat profile (Mok et al. 2008; Syed et al. 2005), and Nd:YAG lasers, modulated to create a "rolo" shaped beam (Shang et al. 2014), have both been used successfully for laser cladding, with some metallurgical improvements.

Although they offer improvements over a $\mathrm{TEM}_{00}$ Gaussian beam, these methods all suffer from a common flaw; which is that they are "fixed format" beam shaping methods. The 
overall laser beam shape can be altered, but that shape cannot be tuned to the specific thermal requirements of the process. This means that the process is governed by the limitations of the laser.

Novel holographic mirrors, Holographic Optical Elements (HOE's), have been developed (Tyrer \& Noden 1996), which use a computer generated kinoform to reshape a TEM 00 laser beam into any desired thermal profile. Instead of trying to achieve the best possible result with a given laser beam, the desired result can be specified first and a HOE designed that creates the specific laser beam profile required to achieve it. The HOE optical train, along with images of the optical elements themselves, are shown in Figure 1.

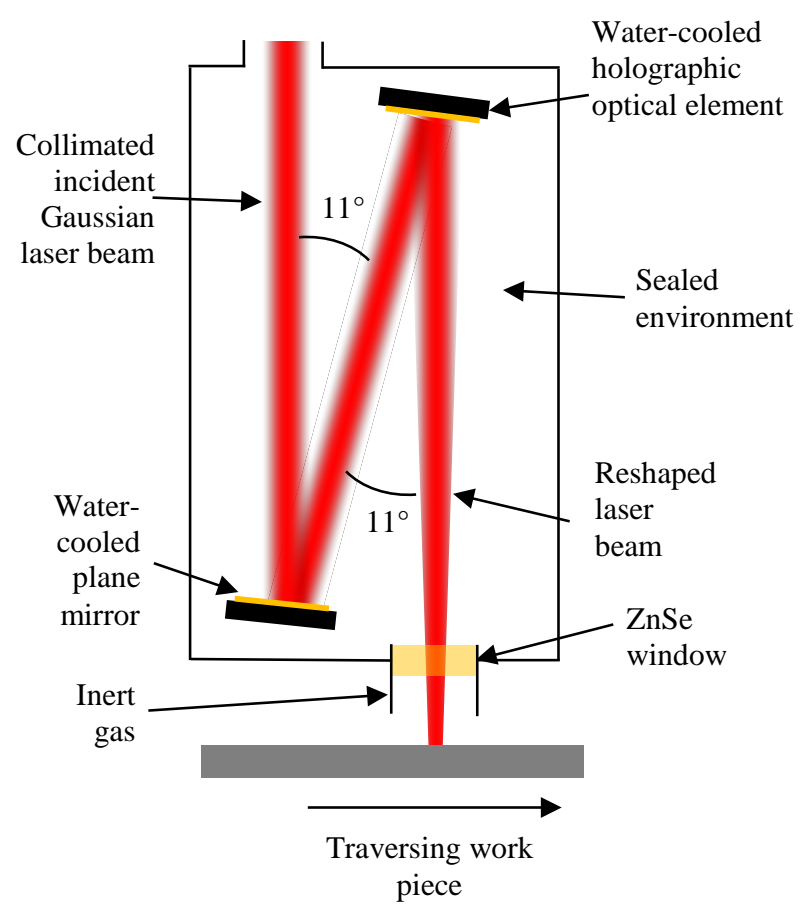

(a)

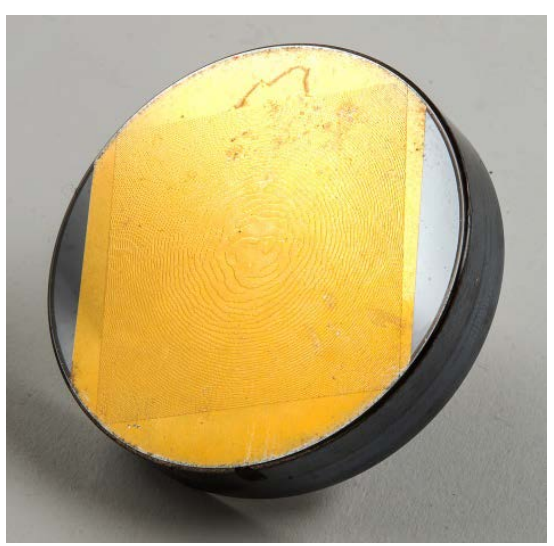

(c)

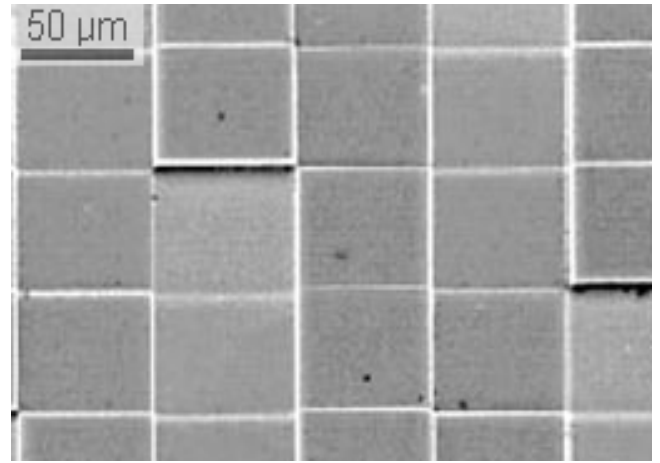

Figure 1: (a) Diagram of HOE beam path (b) Photograph of HOE optic (c) High-magnification SEM image of the HOE surface (Gibson 2012)

High-power HOE systems are designed to use reflective HOE’s rather than transmissive ones, because they can be more easily water cooled for use with high-power lasers. HOE's 
themselves eliminate the need for focussing optics, since the beam shaping capability of the HOE includes the creation of the correct beam size at a specified working distance. This capability is shown in Figure 2, which displays the spatial precision, intensity variation and ability to create different characters of the HOE.

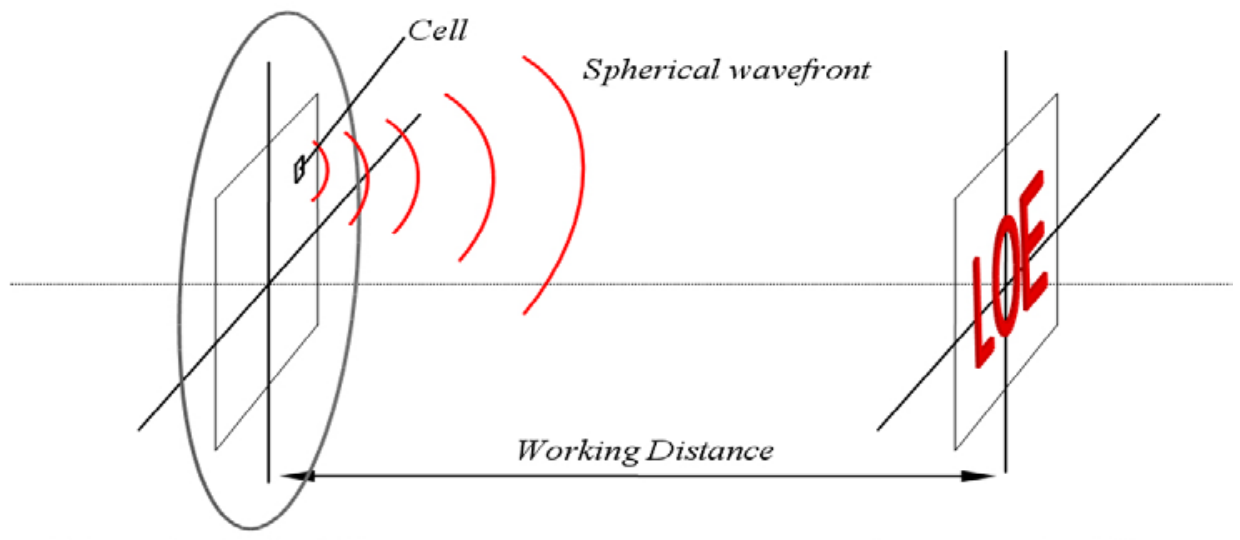

Diffractive Optical Element

(a)

Reconstruction Plane

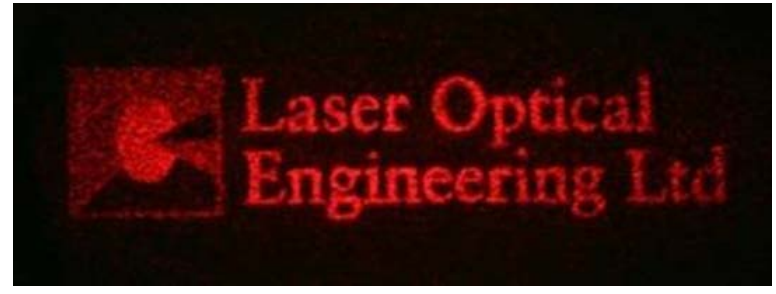

(b)

Figure 2: (a) Schematic of HOE operating principle (b) Resultant complex customised beam (Kell 2007)

HOE's optimised for different processes such as laser hardening, welding, or deposition can swapped in and out depending on the process; making the laser system analogous to a CNC machining system, with the HOE's likened to machine tooling.

HOE’s have previously been used to investigate laser welding and powder-bed laser cladding (Kell et al. 2011; Higginson et al. 2010; Kell 2007; Higginson et al. 2012), experimenting with complex, asymmetrical beam profiles for thermal control. This research has included placing additional heat concentrations in different parts of the beam, as well as the addition of thermal ramps for pre- and post-heating. 
Burn prints created by Kell (Kell 2007), along with computer illustrations, are shown in Figure 1, with the more complex beam shapes that HOE's are capable of. Figure 3 (a) and (b) are identical to the beams used for the experiments described in this paper.

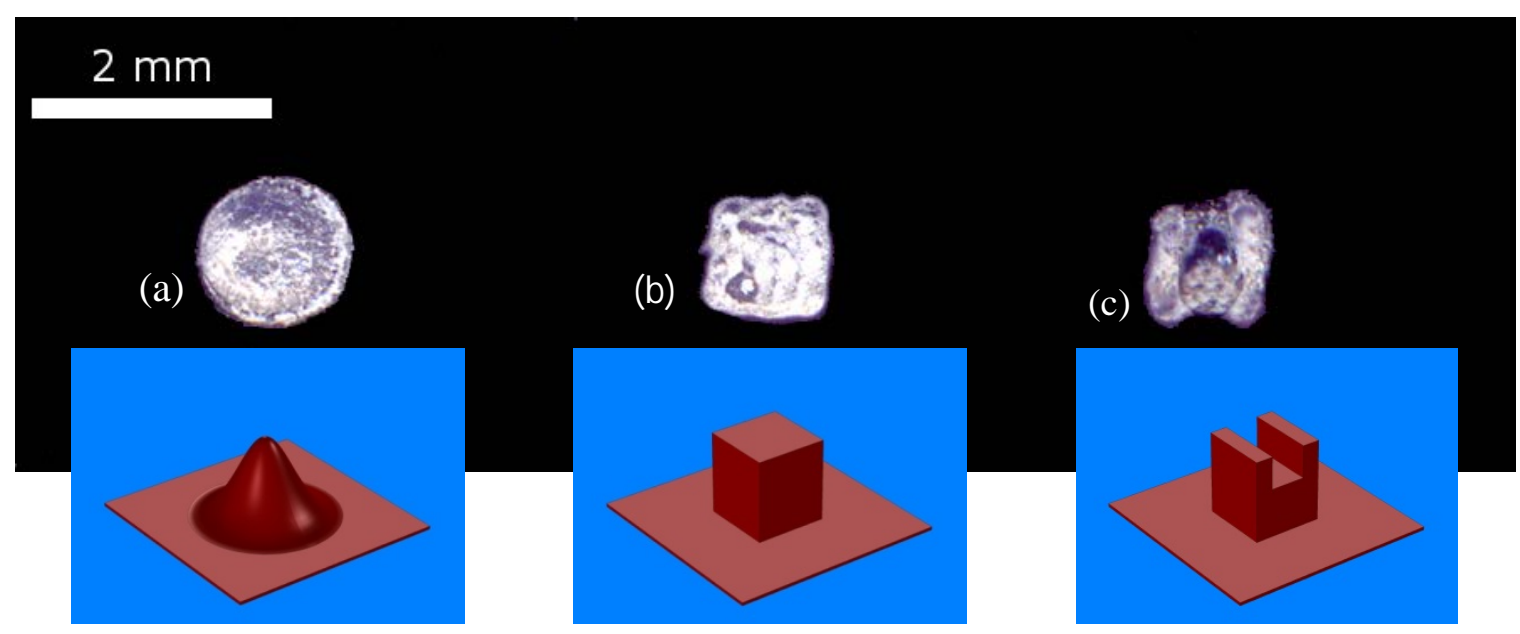

Figure 3: Laser burn prints in perspex of (a) Gaussian beam profile (b) Pedestal beam profile (c) Rugby posts beam profile. Burn prints used with permission (Kell 2007)

The purpose of the present work is to investigate the potential for HOE's to mitigate the recognised disadvantages of wire-based laser cladding, by using a flat pedestal beam for control of heat input.

Apart from using HOE's there is another method producing an even applied heat profile across the width of the wire. This is by expanding the beam diameter. A schematic of how this works is shown in Figure 4. 
(a) $1.25 \mathrm{~mm}$ Gaussian beam

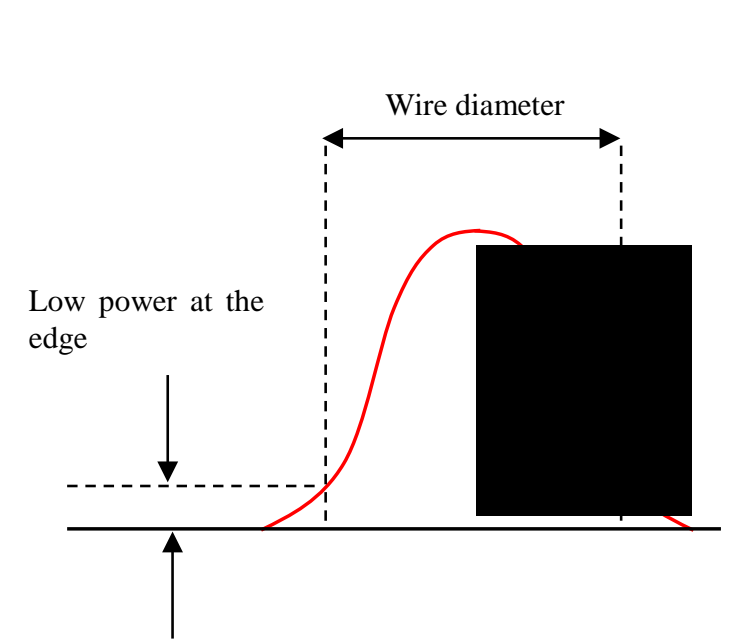

(b) Larger Gaussian beam

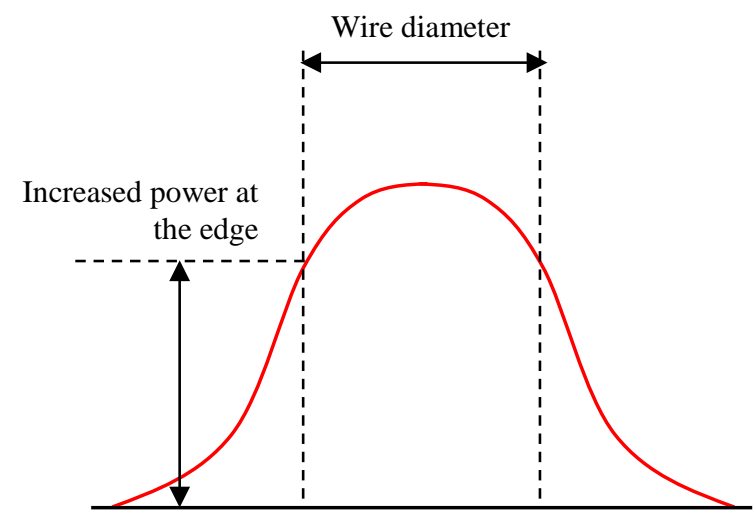

Figure 4: Schematic of applied power distribution when applying (a) $1.25 \mathrm{~mm}$ Gaussian beam and (b) larger Gaussian beam

The use of an expanded Gaussian beam also results in an approximately rectangular heating time profile in a similar fashion to the pedestal HOE. This is shown in Figure 5, with the rectangular heating time profile of the enlarged Gaussian beam shown by the dashed line.

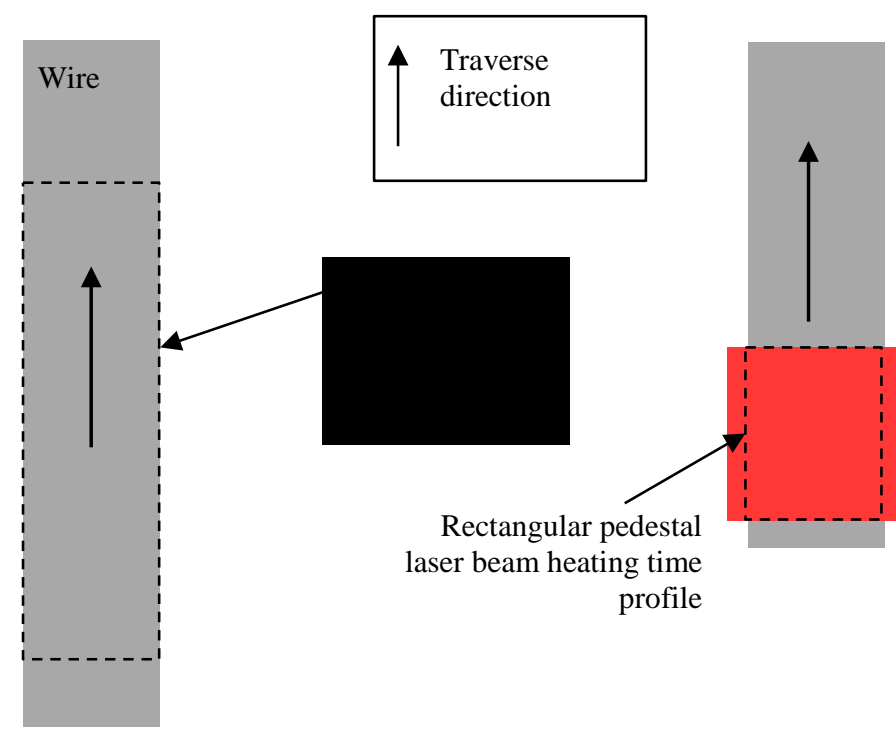

Figure 5: Schematic of heating time profiles for (a) enlarged Gaussian beam and (b) pedestal beam on diameter $1 \mathrm{~mm}$ wire

This method was also compared to the pedestal HOE. 


\section{Experimental procedure}

Experiments were carried out using a Coherent Everlase $\mathrm{S} 48 \mathrm{CO}_{2}$ laser rated at $1.2 \mathrm{~kW}$, with a wavelength of $10.6 \mu \mathrm{m}$ and a nitrogen gas shield. A lens with a focal length of 2.5 ” was used, giving a beam waist at focus of approximately $0.25 \mathrm{~mm}$. The laser was run in CW (Continuous Wave) mode. Mild steel sheet with a thickness of $0.8 \mathrm{~mm}$ was used as the substrate material (alloy composition in Table 1). AISI 316 stainless steel wire with a diameter of $1 \mathrm{~mm}$ was used as the clad material (alloy composition in Table 2).

Table 1: Alloy composition of mild steel (weight \%)

\begin{tabular}{ccccccccc}
\hline Element & $\mathrm{Mn}$ & $\mathrm{C}$ & $\mathrm{Cr}$ & $\mathrm{Cu}$ & $\mathrm{S}$ & $\mathrm{P}$ & $\mathrm{Ni}$ & $\mathrm{Fe}$ \\
& & & & & & & & \\
\hline & 0.791 & 0.154 & 0.079 & 0.045 & 0.018 & 0.017 & 0.017 & balance \\
\hline
\end{tabular}

Table 2: Alloy composition of AISI 316 stainless steel (weight \%)

\begin{tabular}{ccccccccccc}
\hline Element & $\mathrm{Cr}$ & $\mathrm{Ni}$ & $\mathrm{Mo}$ & $\mathrm{Mn}$ & $\mathrm{Si}$ & $\mathrm{Cu}$ & $\mathrm{P}$ & $\mathrm{C}$ & $\mathrm{S}$ & $\mathrm{Fe}$ \\
& 18.26 & 12.09 & 2.53 & 1.61 & 0.42 & 0.12 & 0.02 & 0.11 & 0.01 & balance
\end{tabular}

The substrate was laser-cut to form 12 individual coupons, as shown in Figure 6, with each coupon used to create a clad track. This was done to aid the creation of cross-sections and to prevent any spread of the heat affected zone between samples. 


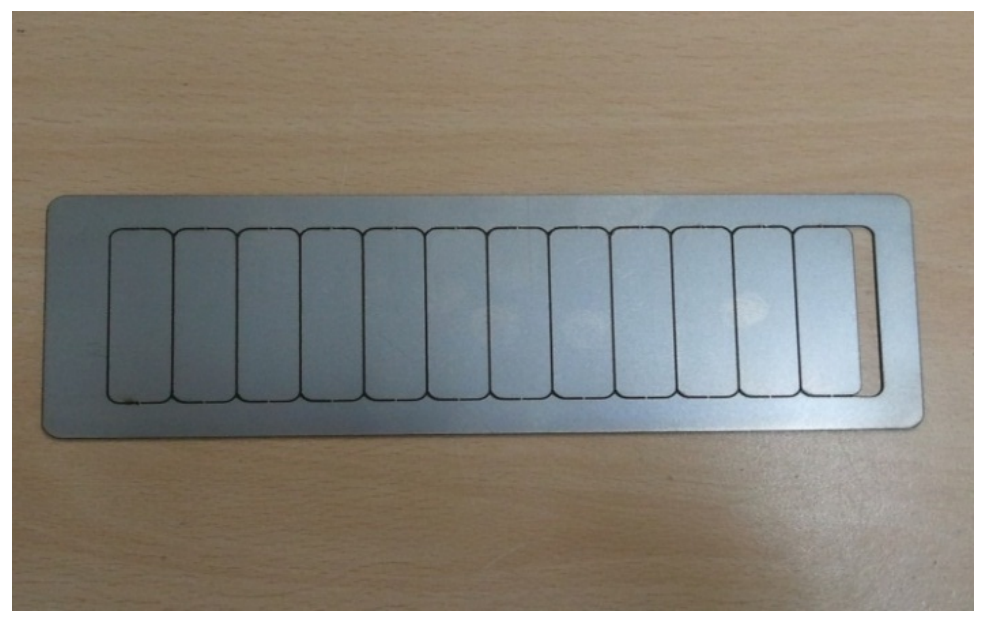

Figure 6: Sample plate with twelve individual sample coupons

Normally, laser cladding with wire is performed with a wire feeder that introduces wire to the melt pool at a defined rate and incidence angle relative to the laser beam, whereas in this study, the wire was pre-placed onto the substrate. This is because consideration of wire feeding adds additional variables to the thermal model such as feed rate, feed angle, whether the wire is heated by the laser beam or fed into an existing melt pool, etc. which were undesirable for the reflectivity model being tested in this study. Pre-placing the wire allowed these variables to be eliminated.

The substrate and wire rested on an insulation brick and was held in place using an aluminium jig (Figure 7). This assembly was then clamped to a CNC table, which was used to traverse the work piece. 


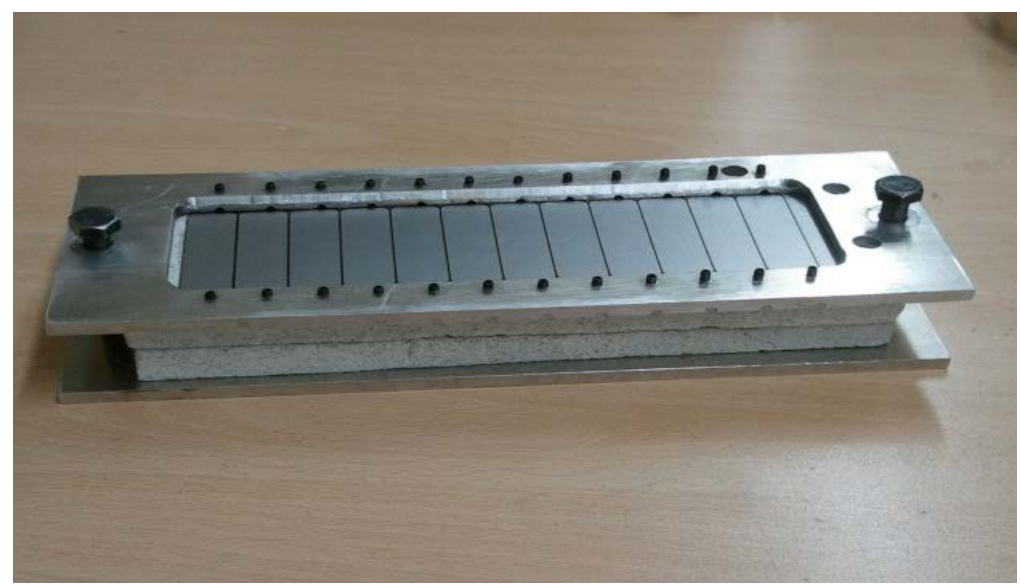

Figure 7 : Sample mounting jig

An initial delay of $4 \mathrm{~s}$ was applied between initiating the laser beam onto the work piece and beginning to traverse it; to enable the generation of the initial melt pool. The wire/substrate assembly was then traversed with a feed rate of $1.6 \mathrm{~mm} / \mathrm{s}$. These parameters optimised the laser output power at its most stable level.

HOE's were used to control the beam profile. Three beam profiles were used:

- Original 1.25 mm diameter Gaussian TEM $\mathrm{T}_{00}$ beam profile, created by defocussing the beam to approximately $3 \mathrm{~mm}$ above the top surface of the wire.

- HOE-generated 1.25 x $1.25 \mathrm{~mm}$ square pedestal profile. The reconstruction plane of the HOE was aligned with the top surface of the wire, giving the correct beam size at that point.

- Expanded 3.5 mm diameter Gaussian $\mathrm{TEM}_{00}$ beam profile, created by defocussing the beam to approximately $6.5 \mathrm{~mm}$ above the top surface

These profiles are shown in Figure 8. 

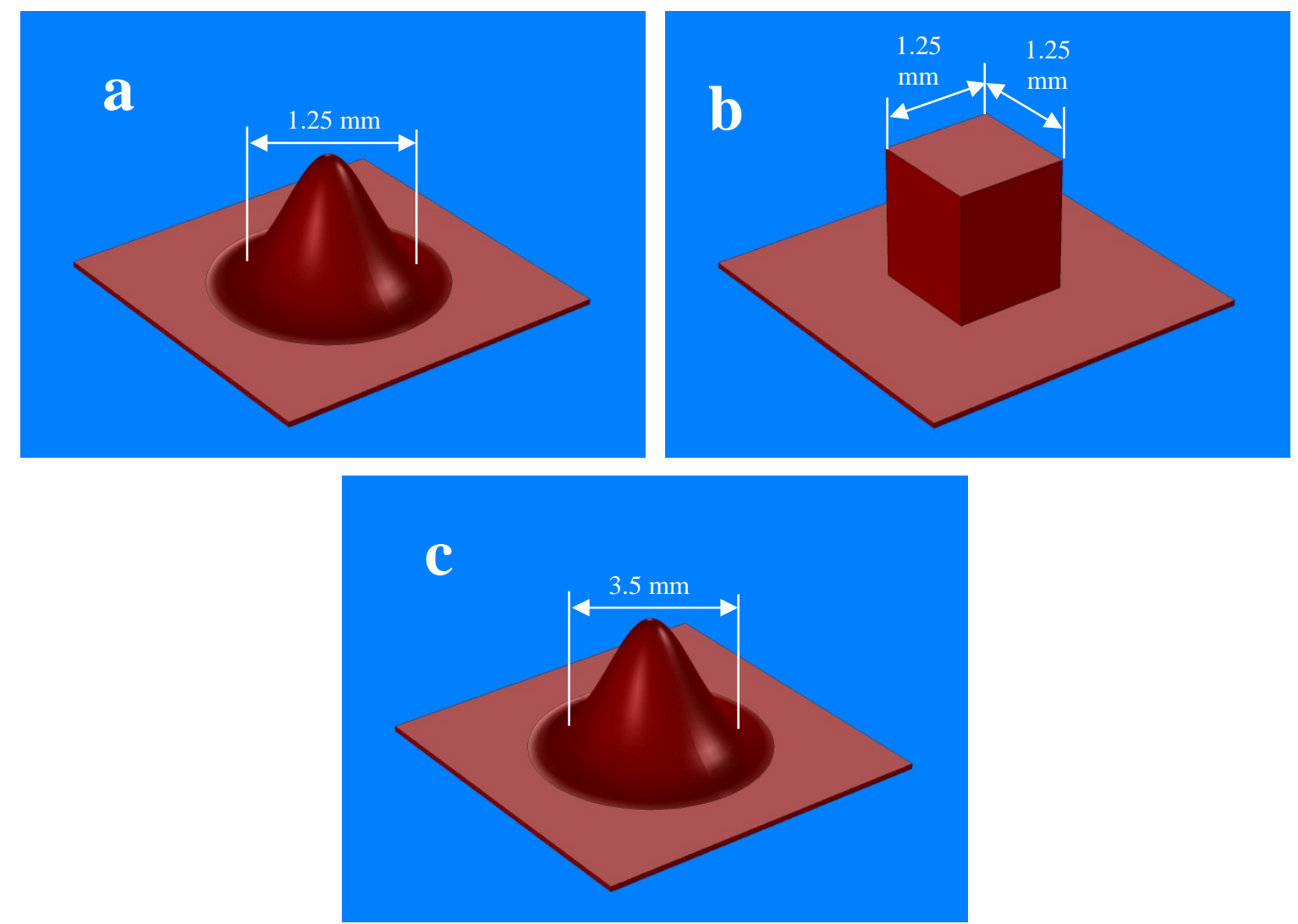

Figure 8: Beam profiles for (a) $1.25 \mathrm{~mm}$ TEM $_{00}$ Gaussian beam and (b) pedestal diffractive beam (c) 3.5 mm TEM$_{00}$ gaussian beam

Use of these beam profiles resulted in two differences in the cladding process:

- Changes in beam cross-sectional shape. The beam cross-sectional shape changed from a circle to a square. For the Gaussian beam, the centre is heated by the full diameter of the beam, whereas the outside is heated by smaller segments, meaning that the total heating time reduces towards the outer parts of the wire. This changes with the square profile of the pedestal beam, which heats every part of the wire for the same amount of time. Figure 9 shows that for a $1.25 \mathrm{~mm}$ Gaussian beam, the illumination time in the centre of the wire (distance 2) is approximately double that at the edge (distance 1). For a $1.25 \mathrm{~mm}$ pedestal beam with the same traverse, both distances are equal across the whole width. Since both beams are traversed at $1.6 \mathrm{~mm} / \mathrm{s}$, this equates to 
$0.8 \mathrm{~s}$ in the centre of the Gaussian beam and $0.4 \mathrm{~s}$ at the edge, while the pedestal is 0.8 s across the entire width.

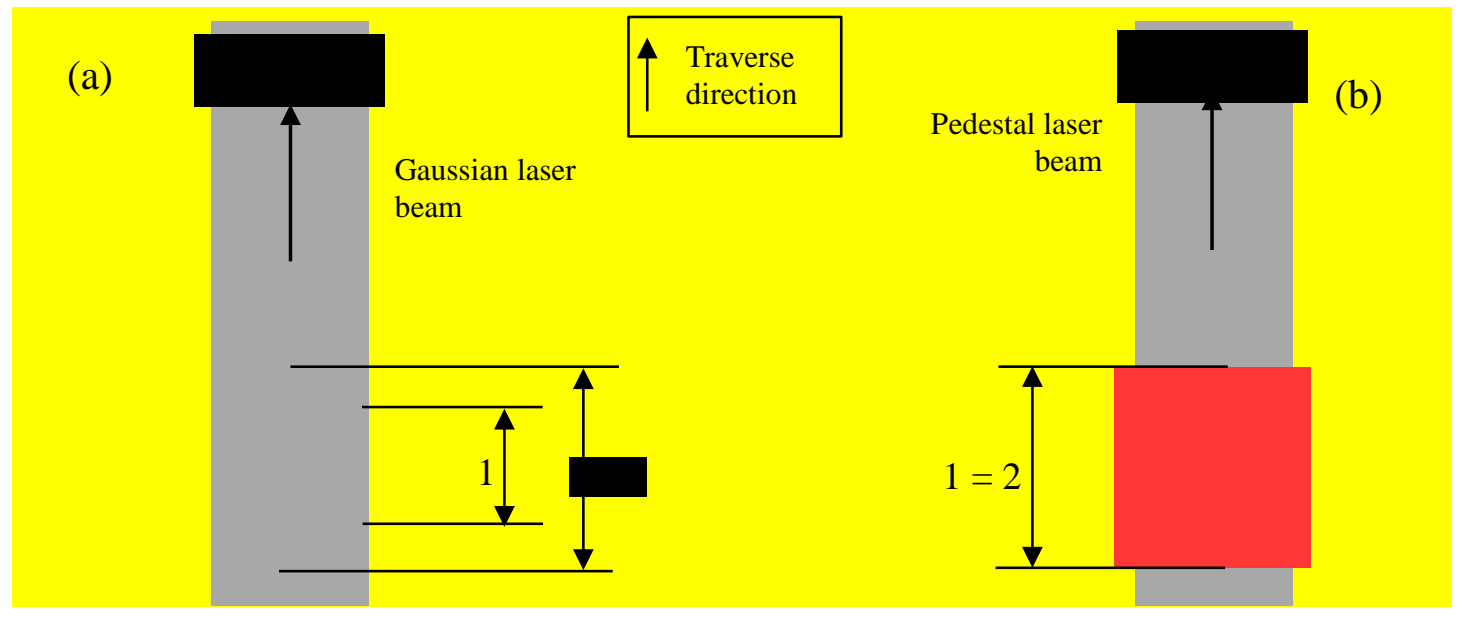

\section{Figure 9: Schematic of heating times for (a) $1.25 \mathrm{~mm}$ Gaussian and (b) $1.25 \mathrm{~mm}$ pedestal beam types}

- Changes in heat distribution. For the Gaussian beam, the majority of the applied energy is concentrated in the centre of the wire, whereas for the pedestal beam, it is evenly distributed across the entire width. Figure 10 shows that the absorbed irradiance at the centre of the wire (distance 1) with a Gaussian beam is approximately twice as high as the absorbed irradiance at the edge (distance 2), neglecting the effects of incidence angle. For the wire with a pedestal beam, it stays constant, neglecting the effects of incidence angle.
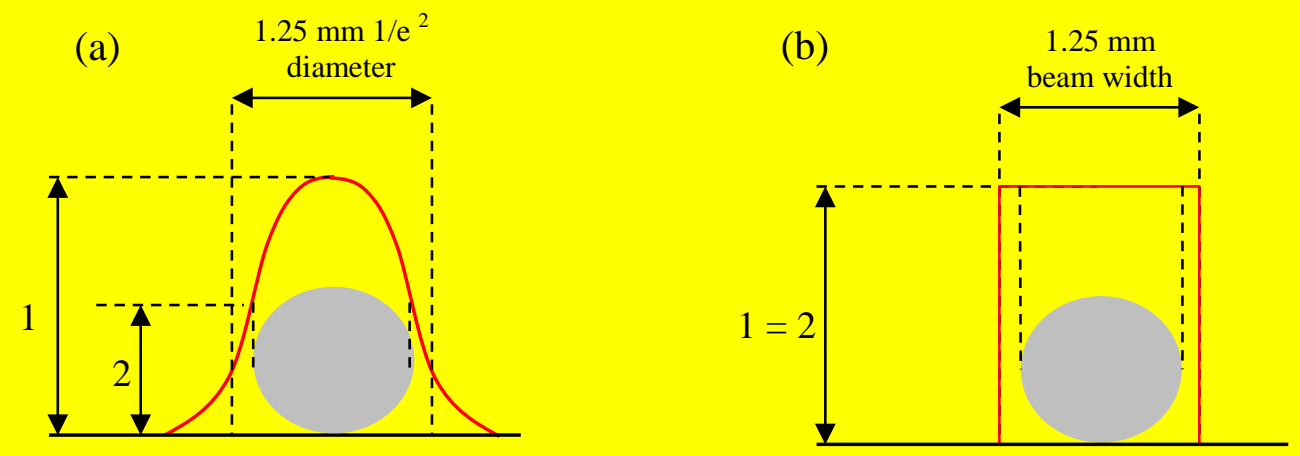

Figure 10: Schematic of absorbed irradiance for (a) $1.25 \mathrm{~mm}$ Gaussian beam and (b) $1.25 \mathrm{~mm}$ pedestal beam types 
Once created, the clad samples were sectioned and mounted in Bakelite. They were then ground, polished to $1 \mu \mathrm{m}$ and etched with Kalling’s No. 2 reagent to reveal the grain structure. Optical micrographs were created using an Alicona Infinite Focus optical microscope and used to measure clad dimensions. Two properties were of interest:

- Wetting angle: This was defined as the external angle formed between the clad surface and the substrate surface and gives a measure of successful clad track creation. A small wetting angle indicates a wire that has adhered to the substrate but not formed clad track, whereas a large angle would indicate a successfully created clad track. This is shown in Figure 11.
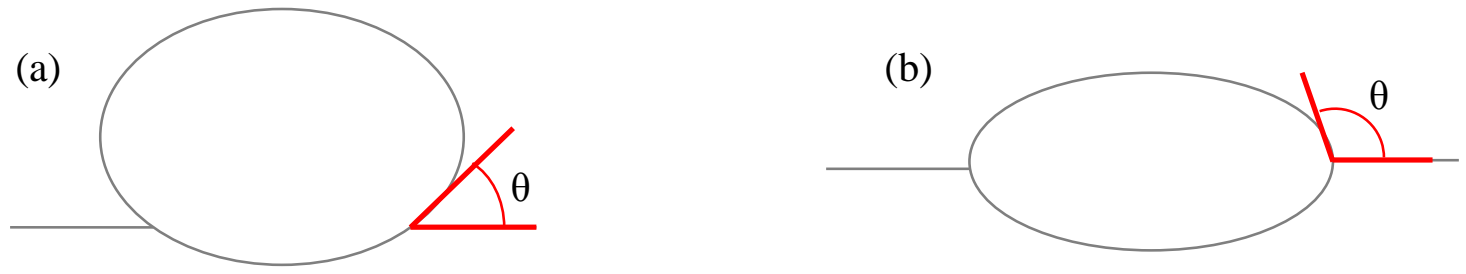

Figure 11: Schematic of wetting angles ( $\theta$ ) showing (a) acute wetting angle, giving poor clad track (b) obtuse wetting angle, giving successful clad track

- Dilution: This was defined as the ratio between the penetrated cross-sectional area (A) and total cross-sectional area (B) as a percentage. A schematic is shown in Figure 12.

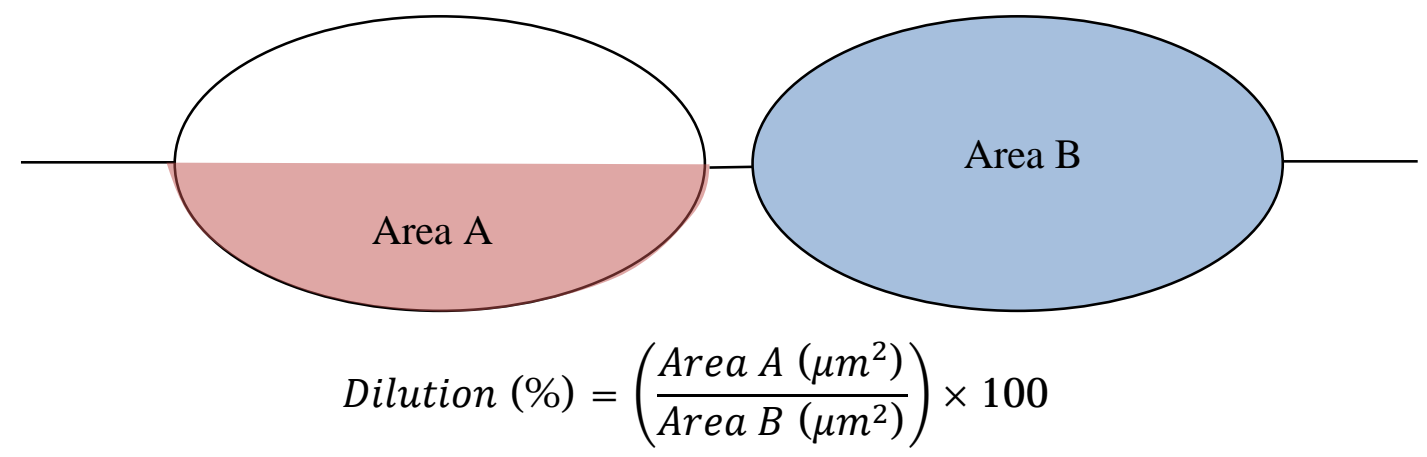

Figure 12: Schematic of dilution definition 
Dilution is a measure of how much the clad has mixed with the substrate and therefore should be as low as possible.

\section{Results and discussion}

Both beam types were tested over a range of power intensities. The ranges were bounded by:

- The lowest power density at which the wire adhered to the substrate. Below this, no clad track could be formed.

- The highest power density, at which the clad track became so highly diluted that it could no longer be considered a separate material from the substrate. It was not possible to create Gaussian clad tracks at equivalent power densities to the pedestal clad tracks.

Figure 13 shows cross-sectional optical micrographs of the clad tracks created with a Gaussian beam at increasing power densities. Figure 14 shows cross-sectional optical micrographs of clad tracks created with a pedestal beam at increasing power densities. 


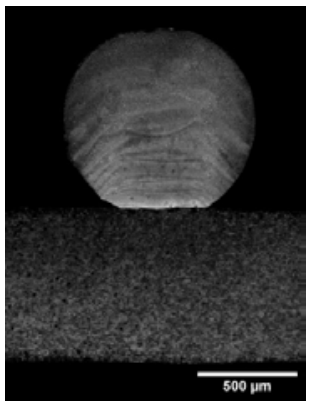

$400 \mathrm{~W} / \mathrm{mm}^{2}$

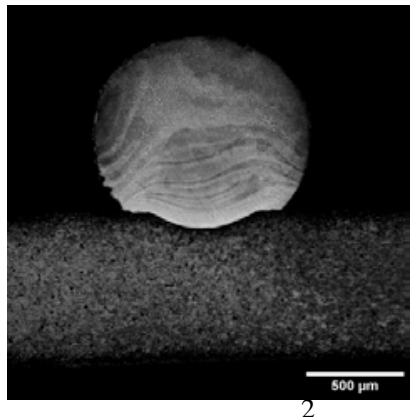

$460 \mathrm{~W} / \mathrm{mm}$

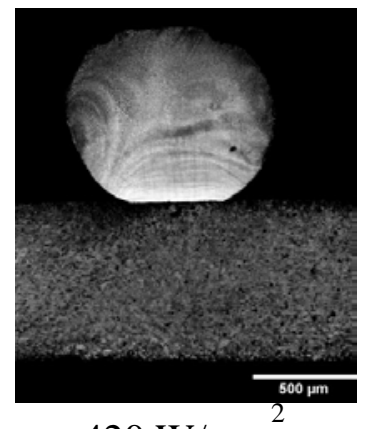

$420 \mathrm{~W} / \mathrm{mm}$

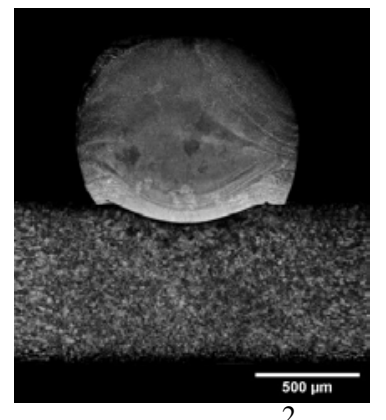

$480 \mathrm{~W} / \mathrm{mm}$

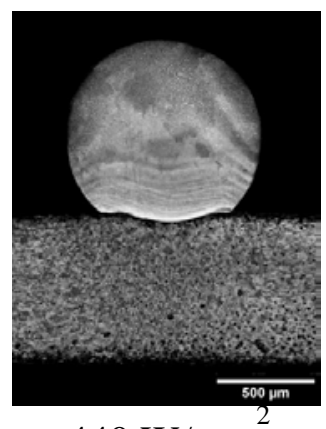

$440 \mathrm{~W} / \mathrm{mm}$

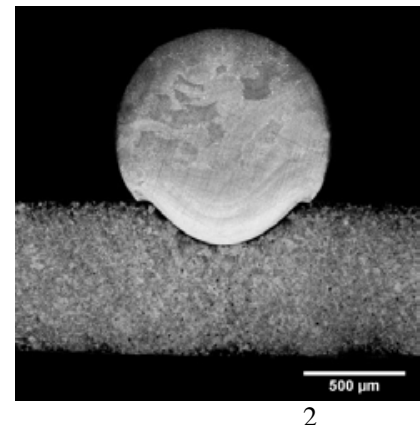

$500 \mathrm{~W} / \mathrm{mm}$

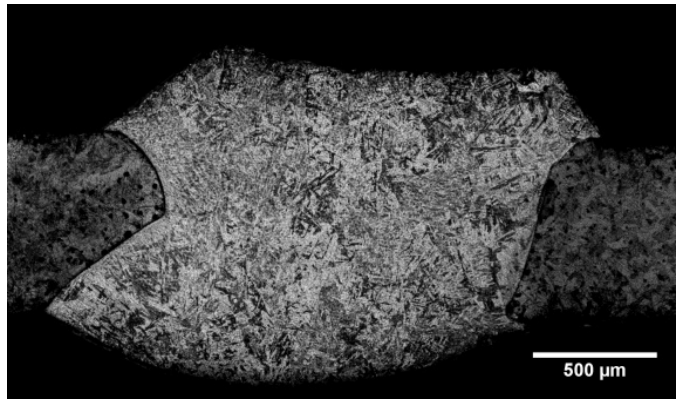

$520 \mathrm{~W} / \mathrm{mm}$

Figure 13: Optical micrographs of clad tracks created with a $1.25 \mathrm{~mm}$ Gaussian beam on pre-placed $1 \mathrm{~mm}$ round wire at increasing power densities 


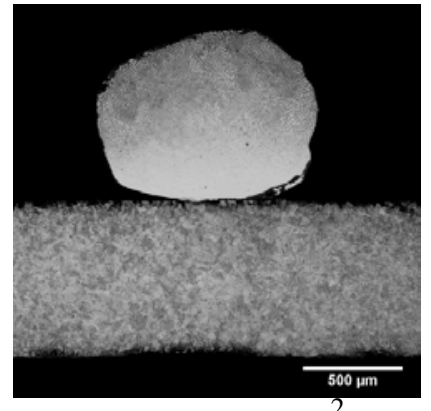

$170 \mathrm{~W} / \mathrm{mm}$

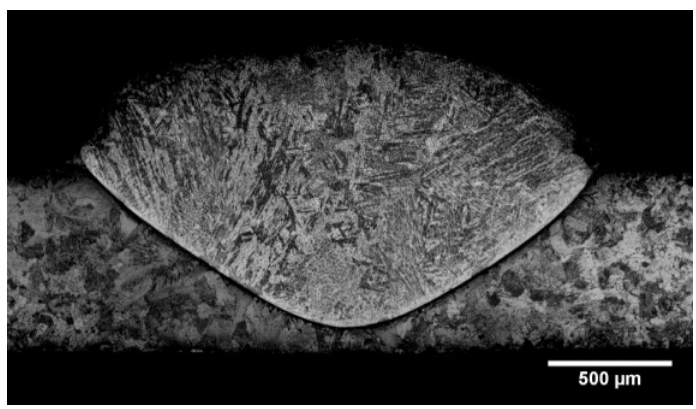

$210 \mathrm{~W} / \mathrm{mm}^{2}$

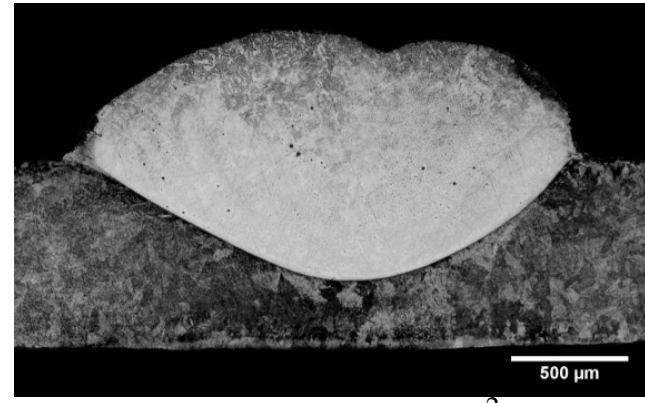

$190 \mathrm{~W} / \mathrm{mm}$

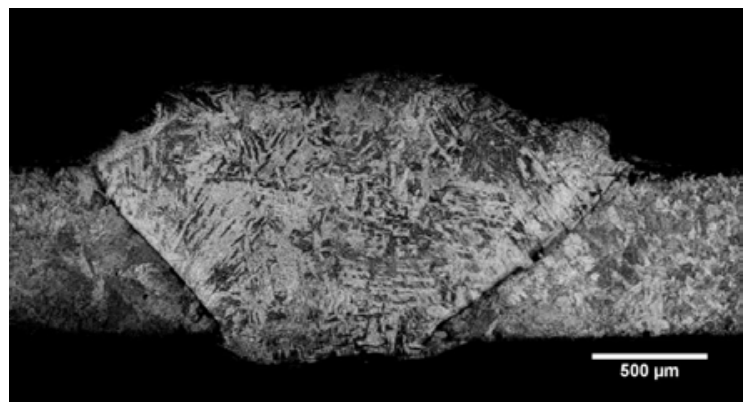

$230 \mathrm{~W} / \mathrm{mm}^{2}$

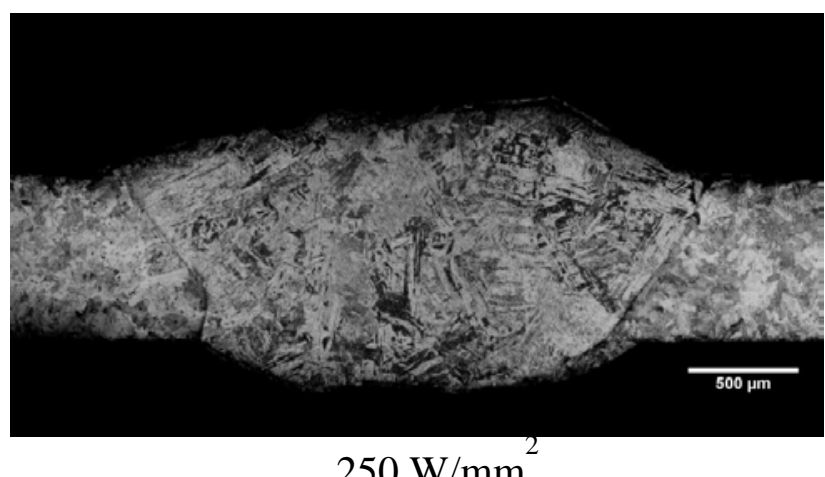

$250 \mathrm{~W} / \mathrm{mm}$

Figure 14: Optical micrographs of clad tracks created with a $1.25 \mathrm{~mm}$ square pedestal beam on pre-placed $1 \mathrm{~mm}$ round wire at increasing power densities

Heating with a $1.25 \mathrm{~mm}$ Gaussian beam resulted in a large thermal gradient. This is evident in the clear flow lines present in the clad sections from Figure 11. At higher power densities the centre of the wire has also penetrated into the substrate material, while the small wetting angles (Table 3) show that the outer regions have not been sufficiently heated to wet the surface of the substrate. 
Table 3: Wetting angles with power densities for Gaussian laser beam

\begin{tabular}{ccc}
\hline $\begin{array}{c}\text { Power density } \\
\left(\mathrm{W} / \mathrm{mm}^{2}\right)\end{array}$ & $\begin{array}{c}\text { Mean wetting angle } \\
\text { (degrees) }\end{array}$ & Dilution (\%) \\
\hline 400 & 37.7 & 2.57 \\
\hline 420 & 40.6 & 1.97 \\
\hline 440 & 46.4 & 2.88 \\
\hline 460 & 46.3 & 4.98 \\
\hline 480 & 54.9 & 8.38 \\
\hline 500 & 64 & 11.95 \\
\hline 520 & 141.3 & 84.37 \\
\hline
\end{tabular}

Once the power density reaches a high enough level, the outside is sufficiently heated, at which point it forms a melt pool. This is shown by the increase in wetting angle and the corresponding increase in dilution. The power density at this level is high enough to cause excessive dilution, where mixing is total and the resultant metal is an alloy of stainless steel and mild steel. The Gaussian experiments transition from adhering with no melt pool to full mixing with a power density increase of only $20 \mathrm{~W} / \mathrm{mm}^{2}$.

In contrast, heating with a pedestal beam produces a melt pool with very little extra power from that required to make the wire adhere to the surface. The increase in wetting angle between $170 \mathrm{~W} / \mathrm{mm}^{2}$ and $190 \mathrm{~W} / \mathrm{mm}^{2}$ shown in Table 4, along with the dilution increase between the same samples, indicates the point at which the wire changes from just adhering to the surface to forming a melt pool.

Table 4: Wetting angles at various power densities for Pedestal laser beam

\begin{tabular}{ccc}
\hline Power density $\left(\mathrm{W} / \mathrm{mm}^{2}\right)$ & Mean wetting angle (degrees) & Dilution (\%) \\
\hline 170 & 18.8 & 0.19 \\
\hline 190 & 136.5 & 58.71 \\
\hline 210 & 138.4 & 59.41 \\
\hline 230 & 143.5 & 70.61 \\
\hline 250 & 147.8 & 70.54 \\
\hline
\end{tabular}


Once a melt pool is established, the increase in mixing with power density increase is much less extreme than with the Gaussian beam. The increase in power density between melt pool formation and full mixing is $60 \mathrm{~W} / \mathrm{mm}^{2}$ compared to $20 \mathrm{~W} / \mathrm{mm}^{2}$ for the Gaussian beam. This wider range means that the process is less sensitive to disturbances, which mitigates one of the primary weaknesses of the wire-fed process.

The pedestal clad tracks display no visible flow lines, indicating that Marangoni flow is much reduced although the central surface indentations present in the pedestal tracks indicate that it is still present. This is shown in Figure 15.

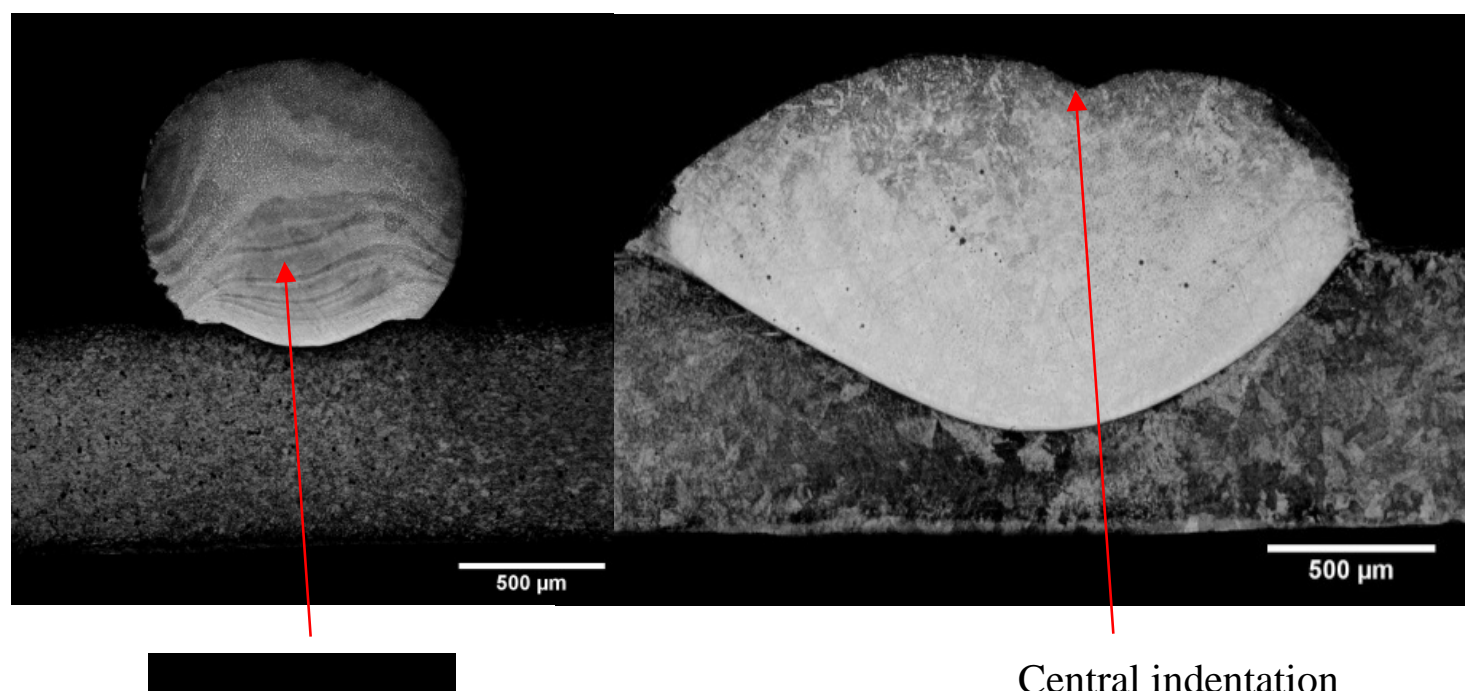

Figure 15: Flow lines and central indentation for Gaussian and holographic clad tracks

The larger grain size in the substrate of the pedestal clad track indicates a slower cooling rate in the substrate. Since the substrates are the same size and the same material this suggests that a higher substrate temperature is reached for the pedestal track during the cladding process. The pedestal track is also much more diluted than the Gaussian track, even though it was created at a lower power density and, with the reduced Marangoni flow, at a lower temperature. This suggests that the use of a pedestal beam allows more efficient conduction of heat into the substrate. 


\section{The effects of enlarging the Gaussian beam size}

Another possible method of creating an even heat profile is to enlarge the Gaussian beam to a wider diameter. This creates a transverse absorption profile that is almost identical to that of a pedestal beam. Experiments carried out to compare a $1.25 \mathrm{~mm}$ pedestal beam and a $3.5 \mathrm{~mm}$ Gaussian beam under ideal conditions gave the micrographs shown in Figure 16.

Both beam types produce similar clad tracks to each other, but the one created with a $3.5 \mathrm{~mm}$ Gaussian beam is much more highly penetrated in the centre. In addition, there are differences between the microstructures.
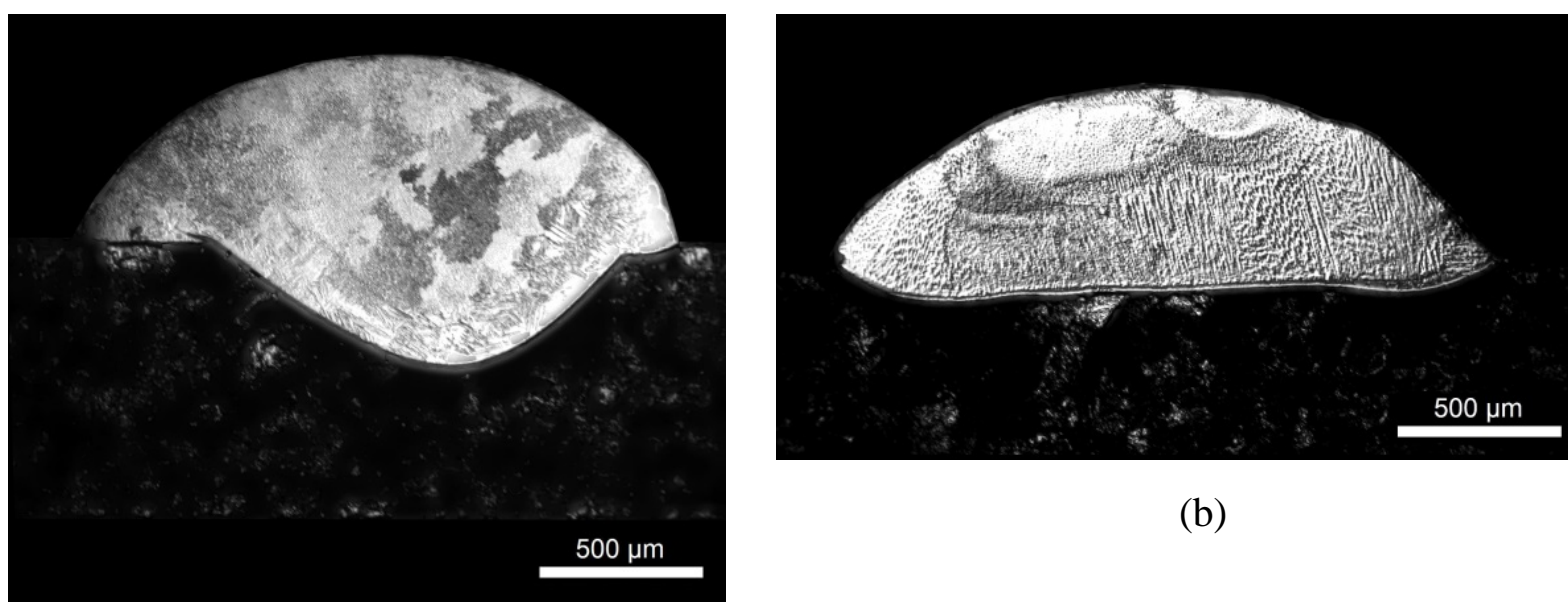

(b)

(a)

Figure 16: Optical micrographs showing (a) clad track created with a $3.5 \mathrm{~mm}$ Gaussian beam and (b) a clad track created with a $1.25 \mathrm{~mm}$ pedestal beam. Both were etched with Schaftmeister's reagent and illuminated using Diffractive Interference Contrast.

Using a grain boundary etch (Schaftmeister's reagent), the grain sizes for both tracks were measured. This showed far longer dendritic grains in the pedestal track than the Gaussian track, indicating more rapid cooling in the Gaussian track. In addition, the non-dendritic regions of the Gaussian track showed an average grain size of $23700 \mu \mathrm{m}^{2}$ vs. $30700 \mu \mathrm{m}^{2}$ for the pedestal beam, supporting this hypothesis 


\section{Evaluation of wire reflectivity profile}

Since the wire has a curved top surface, it is possible that changes in incidence angle and reflectivity across its width could affect the heat absorption. In this section, the heat input profiles used for experimentation were input into a theoretical reflectivity model, to assess the effect of wire shape on heat absorption. These reflectivity calculations were conducted assuming that the wire was held horizontally, in the same manner in which it was processed for experiments. This assumption can be modified to take account of wire feed angle.

The optical reflectivity of any given metal is determined by the interaction of three factors:

- The reflectivity of the metal itself. This is governed by its electrical conductivity, meaning that the most conductive metals are also the best reflectors (Hecht 2002). Since electrical conductivity is also a function of temperature, the temperature of the metal also affects the reflectivity; reflectivity decreases with increasing temperature.

- The wavelength of the incident light. Generally, the longer the wavelength the higher the reflectivity of the metal. This means that the reflectivity from a $1 \mu \mathrm{m} \mathrm{Nd:YAG}$ laser is lower than that from a $10.6 \mu \mathrm{CO}_{2}$ laser.

- The angle of incidence. Incidence angle is related to reflectivity by use of Fresnel relations. This is also highly dependent on the polarity of the light in question.

Outside of temperature dependence and surface treatment effects, these factors are governed by the refractive index of the metal in question. This is a complex number, in the form:

$$
m=n-j k
$$

where $m$ is the complex index of refraction, the real part $n$ is the refractive index and the imaginary part $k$ indicates the absorption at a given wavelength (known as the Absorption Index or Damping Constant) (Modest 2001).

Since a $\mathrm{CO}_{2}$ laser was used for experimentation, reflectivity data for this wavelength (10.6 $\mu \mathrm{m})$ was used. Reflectivity of steel is highly dependent on phase, but changes very little for 
different grades of steel within a given phase, i.e. AISI 304 stainless steel and AISI 316 stainless steel are both austenitic so their $n$ and $k$ values are virtually identical. This means that although calculations are presented using AISI 304, the results are still valid for AISI 316, which was used for the physical experiments (Karlsson \& Ribbing 1982).

Work by Boyden and Zhang (Boyden \& Zhang 2006) determined the $n$ and $k$ values for AISI 304 at $10.6 \mu \mathrm{m}$. These are shown in Table 5.

Table 5: Index of refraction of AISI 304 stainless steel at $\lambda=10.6 \mu \mathrm{m}$ (Boyden $\&$ Zhang 2006)

\begin{tabular}{lll}
\hline $\begin{array}{l}\text { AISI } 304 \quad \text { stainless } \\
\text { steel at } \lambda=10.6 \mu \mathrm{m}\end{array}$ & $\mathrm{n}$-value & $\mathrm{k}$-value \\
\hline & 20.4 & 21.5 \\
\hline
\end{tabular}

\section{Evaluation of round wire top surface}

For a stainless steel wire illuminated by $10.6 \mu \mathrm{m}$ laser radiation, the incidence angle is the variable that governs its absorptivity. Because the wire has a circular cross-section, the angle of incidence is treated as being the angle between incident light and a line normal to the tangent to the cross-section at that particular point. As the transverse distance from the centre line increases, the angle of incidence increases as well; this results in changes in absorptivity, as illustrated in Figure 17:

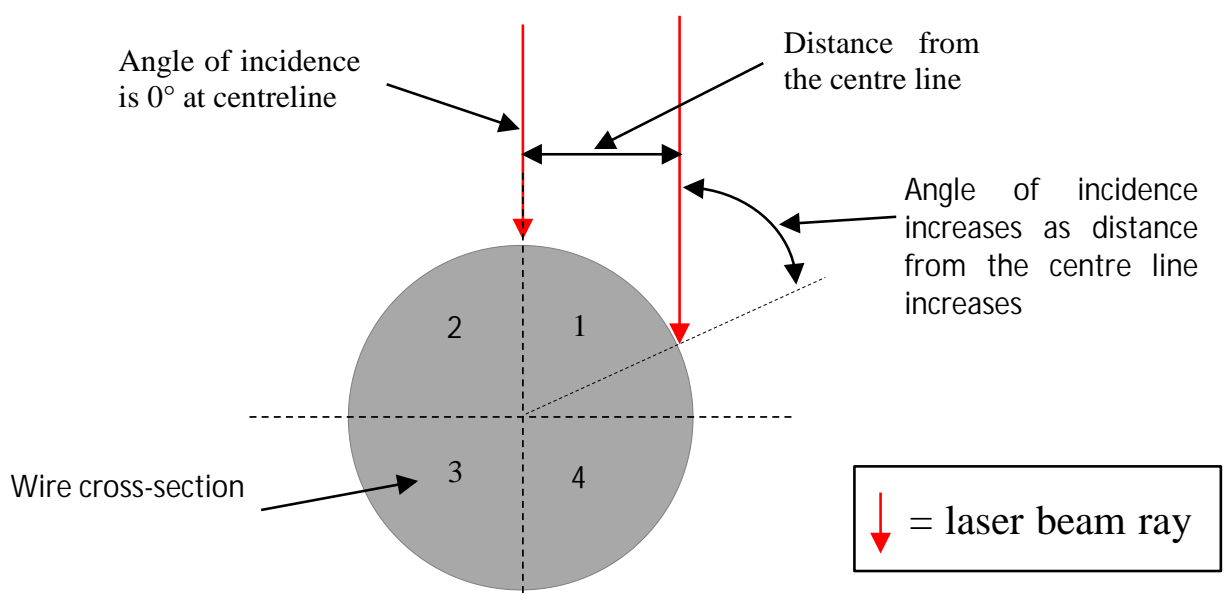

Figure 17: Schematic of how incidence angle changes with centreline distance 


\section{Calculation of incidence angles}

To evaluate the change in incidence angle across the width (transverse distance between the outer edges), the wire was divided into four quadrants (numbered in Figure 11). Quadrants 3 and 4 could be ignored because they are not illuminated by the laser light. Quadrants 1 and 2 are symmetrical, so only Quadrant 1 was considered, since its results could be mirrored in the $y$-axis to account for the whole width of the wire.

The mathematical expression for a circle is:

$$
x^{2}+y^{2}=r^{2}
$$

Where $r$ is the radius of the circle, and $x$ and $y$ are distances from the centre, in the directions of their respective axes.

The quadrant was divided up into twenty sections, with twenty-one points selected in the $\mathrm{x}$ axis. These values were then used to calculate the corresponding values on the y-axis.

Implicit differentiation applied to Equation 1 was used to convert these co-ordinates into gradients:

$$
y^{\prime}=-\frac{x}{y}
$$

The gradients were then converted into incidence angles:

$$
\theta=\tan ^{-1} y^{\prime}
$$

This revealed a largly linear relationship between transverse distance and incidence angle. This relationship is shown in Figure 18. 


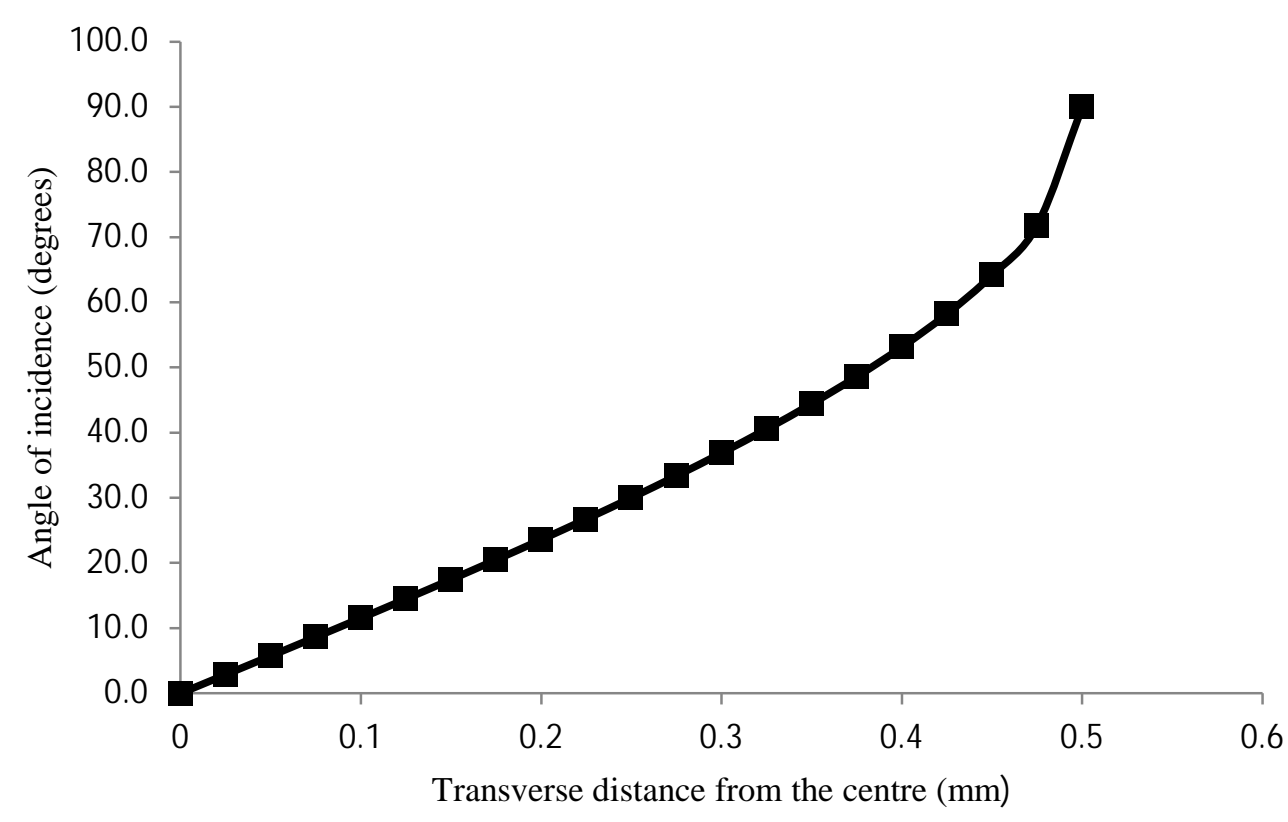

Figure 18: Graph of incidence angle vs. centreline distance for circular cross-section wire

\section{Reflectivity across the width of the wire}

Fresnel relations take into account both the wavelength of the laser beam (via $n$ and $k$ values) and the incidence $\left(\theta_{\mathrm{i}}\right)$ and refraction $\left(\theta_{\mathrm{r}}\right)$ angle. In metals, because the values for $n$ and $k$ are relatively large, these two angles can be assumed to be the same (Modest 2001), and the Fresnel equations simplify to:

Parallel-polarised light:

$$
\rho_{\|}=\frac{(n \cos \theta-1)^{2}+(k \cos \theta)^{2}}{(n \cos \theta+1)^{2}+(k \cos \theta)^{2}}
$$

Perpendicular-polarised light:

$$
\rho_{\perp}=\frac{(n-\cos \theta)^{2}+k^{2}}{(n+\cos \theta)^{2}+k^{2}}
$$

Circular-polarised light (Equation 6) can then be described as an average of Equations 4 and 5 with the following:

$$
\rho=\frac{\rho_{\|}+\rho_{\perp}}{2}
$$


Evaluating each polarisation and using the incidence angles previous calculated gave a reflectivity distribution across the width of the wire shown in Figure 19.

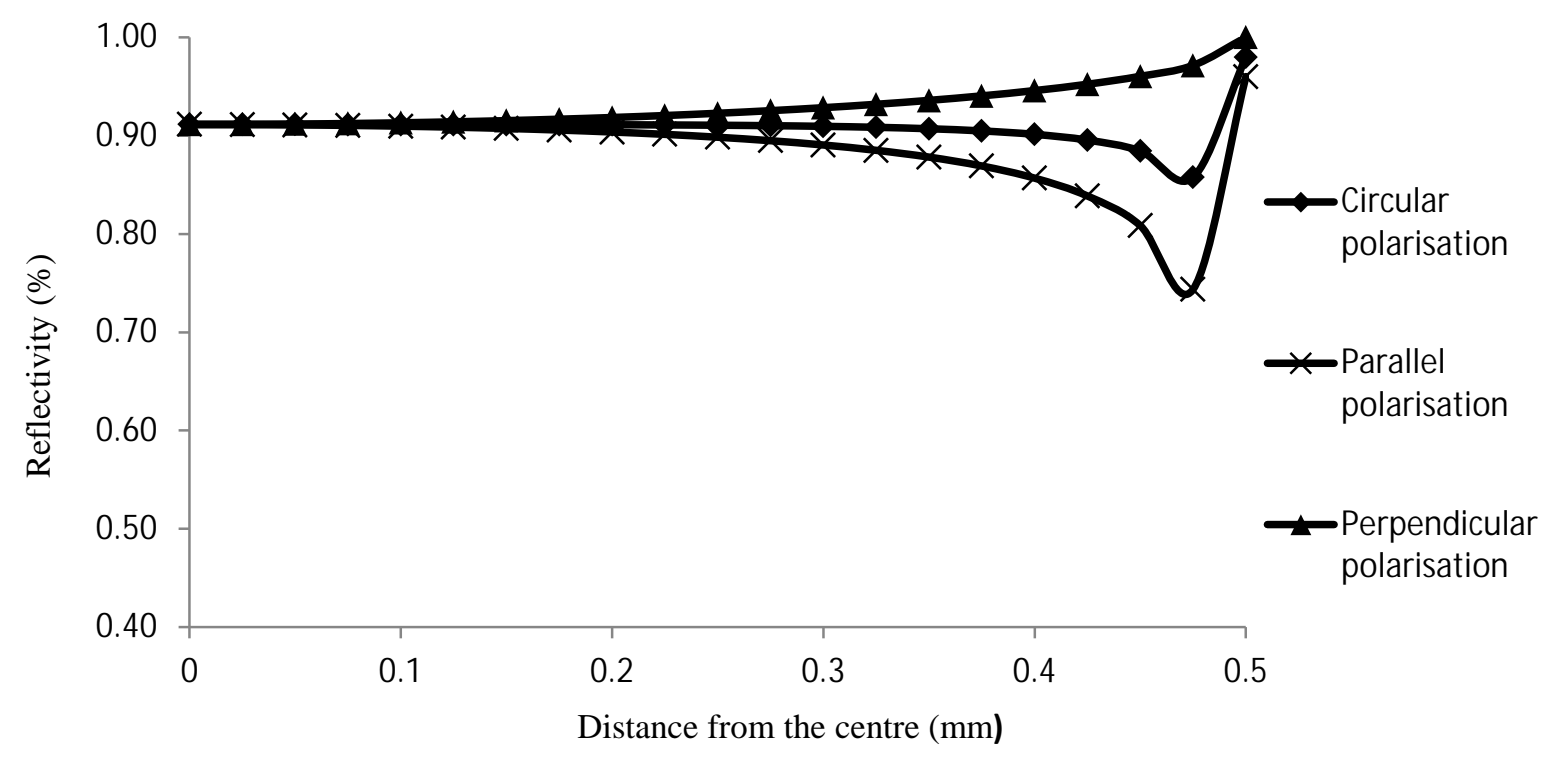

Figure 19: Graph of reflectivity vs. transverse distance from the centreline

For perpendicular polarisation, the absortivity decreases with increasing distance, whereas with parallel polarisation it increases to a maximum corresponding to an incidence angle of approximately $70^{\circ}$, before dropping back to zero. Circularly polarised light is an average of these two. The laser used for experiments was circularly polarised, so this reflectivity profile was carried forward.

Theoretical heat profiles could then be applied to this reflectivity profile to calculate their effects on the wire.

\section{Application of laser heat profiles onto round wire}

Two heat profiles were applied: A TEM ${ }_{00}$ Gaussian profile and a square pedestal profile. The beam widths were set as $1.25 \mathrm{~mm}$. This was to align the model with experimental conditions. The laser power was set at a nominal 100W. Irradiance was calculated at distances $r$, set to be the same as in the reflectivity calculations and was then multiplied by the reflectivity at each 
point, giving a measure of the energy absorbed at each point along the width. The beam was assumed to be circularly polarised.

To calculate the effect of a Gaussian heat profile on the wire, a 1-dimensional Gaussian function was used (Hecht 2002):

$$
I=I_{0} e^{\frac{-2 r^{2}}{w^{2}}}
$$

Where $I$ is the irradiance at point $r, I_{0}$ is the maximum irradiance at the centre point, $r$ is the transverse distance from the centre point and $w$ is the radius at the $1 / \mathrm{e}^{2}$ point.

The resultant absorbed heat profiles are shown in Figure 20.

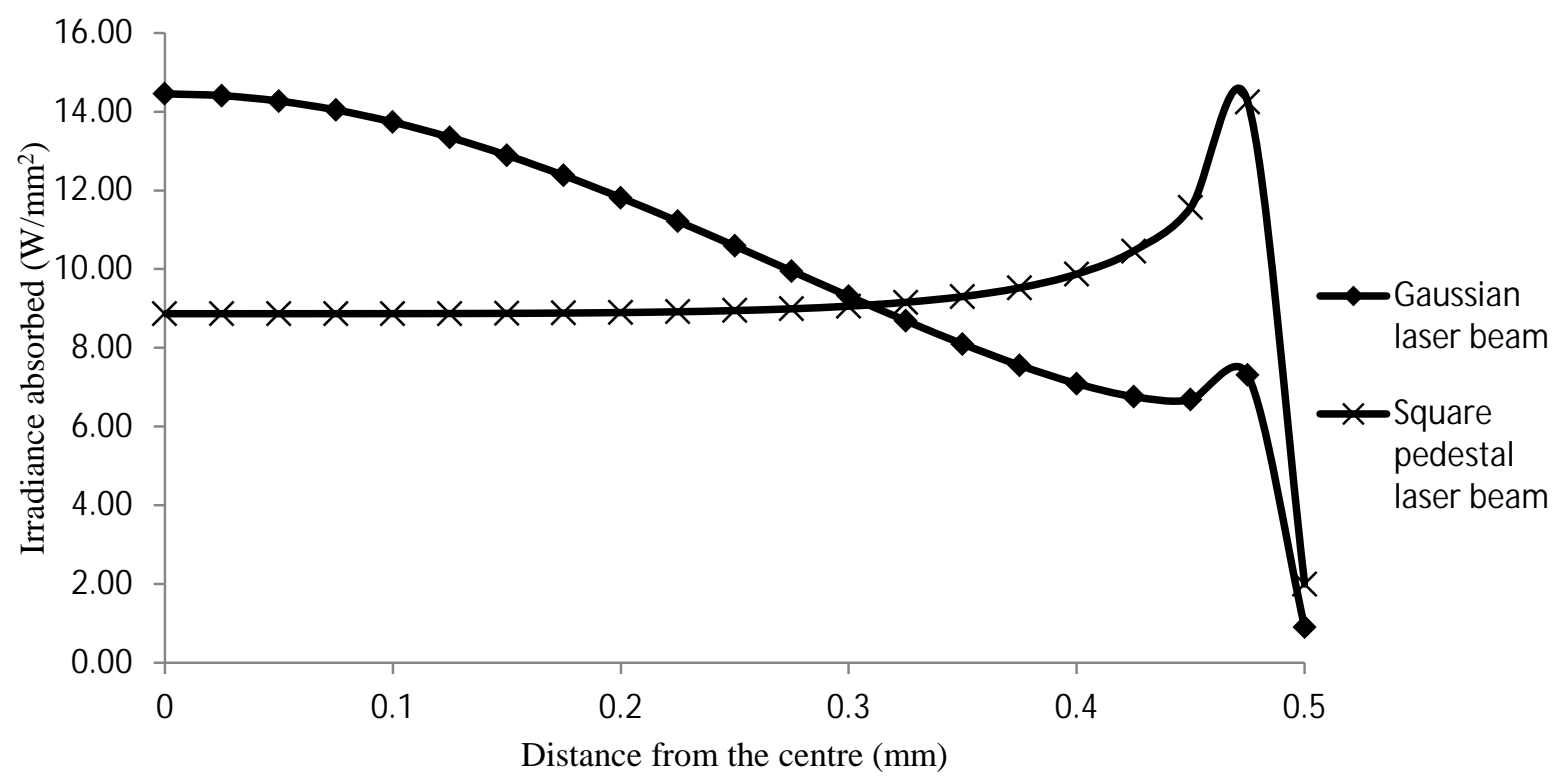

Figure 20: Absorbed irradiance distributions for Gaussian and pedestal laser beam profiles with distance from the centre line

Irradiance absorption is highly dependent on beam shape for the bulk of the width of the wire. Incidence angle only affects the outer $20 \%$ of the width, and affects the pedestal distribution much more strongly. Application of a Gaussian beam results in high absorption at the centre of the wire and less at the edge (with a small increase at the outer edge due to the increased absorption from the increased incidence angle), whereas the pedestal has an even heat 
absorption except where the reflectivity of the wire reduces, at which point the absorption spikes.

\section{Optical effects of wire feeding}

When wire feeding is used, the wire is fed into the melt pool at a certain rate and feed angle.

The overall incidence angle for a wire feeder is a combination of the transverse incidence angles previously calculated, and the tilt angle of the feeder itself.

Figure 21 shows that the optimal incidence angle for wire absorption is approximately $70^{\circ}$ :

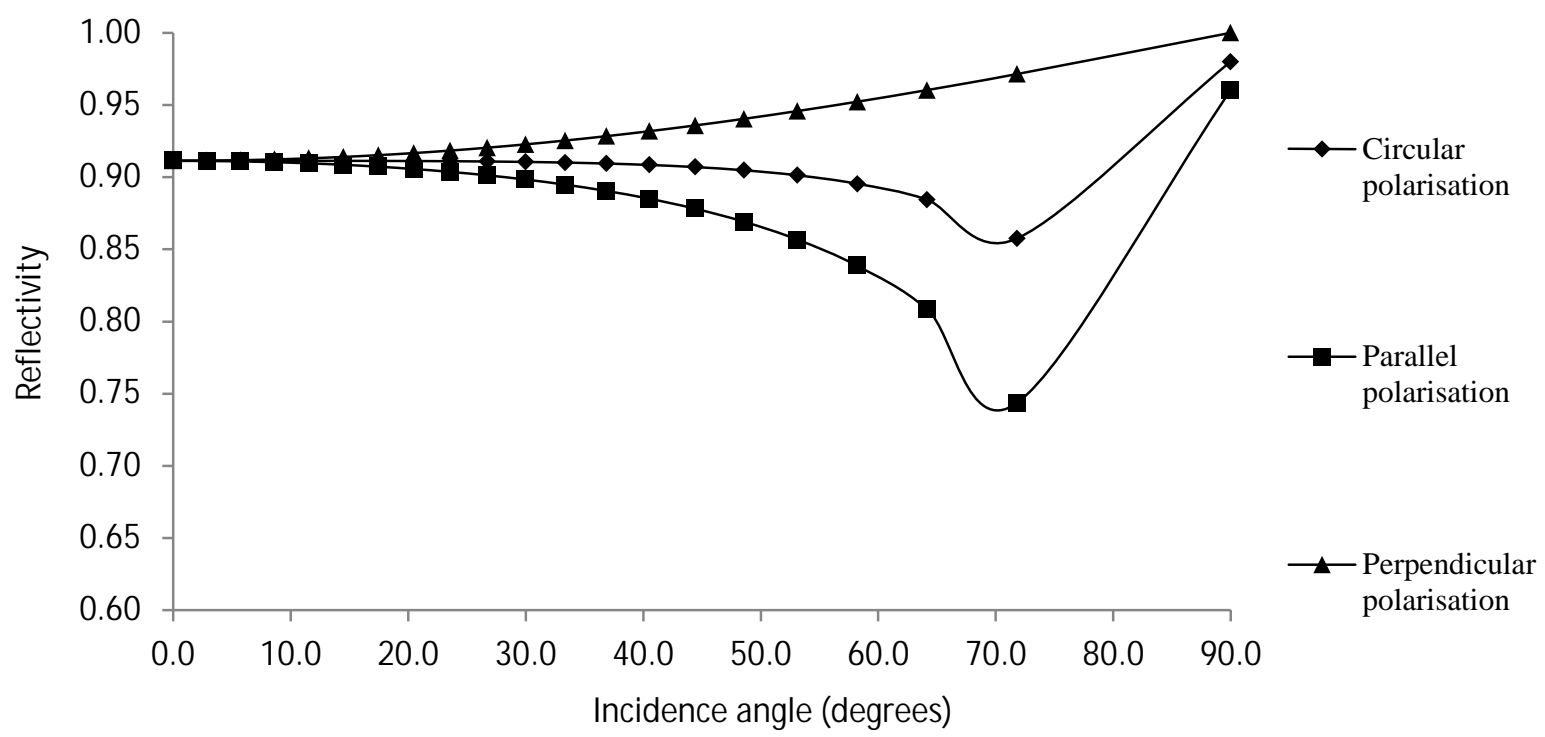

Figure 21: Graph of Reflectivity vs. Incidence angle for stainless steel illuminated with a 10.6 m laser beam

The transverse reflectivity profile of the wire changes across its width, so there is no tilt angle that can give optimum reflectivity everywhere at once. In addition, Figure 13 shows that the reflectivity changes very little over the majority of the width of the wire. Although the wire has a circular cross-section, from the point of view of reflectivity it is virtually flat. For wire feeding, $70^{\circ}$ is the optimum feed tilt angle, as measured between the wire and the substrate. 


\section{Discussion of calculations}

The applied beam shape has a far greater effect on the wire absorption profile than the reflectivity profile of the wire. A round wire cross-section does give increased absorption at the edge, but the effects are minor. When a pedestal beam is applied, the additional irradiance applied to the edge region causes a much larger spike in absorption compared to the Gaussian beam, which serves to enhance its own effects of applying more heat to the edge.

Calculations show that there is a difference between using incidence angle to alter the distribution of irradiance absorption and using it to alter the magnitude of irradiance absorption. The effect of incidence angle on absorption distribution is dependent on the irradiance distribution; a bigger effect was demonstrated with a pedestal beam than with a Gaussian beam. The irradiance distribution, and thus the absorption distribution, can be easily controlled using HOE’s.

The incidence angle can however be used to control the magnitude of the absorption. The maximum absorptivity of the wire occurs when the angle of incidence is approximately $70^{\circ}$. When this is applied to wire feeding, it means that, for example, wire could be tilted at such an angle so as to create an incidence of $70^{\circ}$ relative to the laser beam, to maximise its absorption. This could be easily achieved by use of a wire feeder set at the appropriate feeding angle, moving from the pre-placed wire in this study to classical wire feeding. Additional effects of wire feed rate and feed angle, which have been hitherto disregarded, would then also have to be considered and accounted for.

\section{Conclusions}

The following conclusions were drawn from this work:

- There are particular advantages to the use of HOE's in laser processing, over the use of diode lasers and other forms of optics, with regard to their ability to customise the 
beam shape. This capability has not been taken past the formation of pedestal beams in this case, but has been demonstrated to be of benefit in previous experiments. It should be noted, however, that an advantage of diode lasers over $\mathrm{CO}_{2}$ is their greater absorption properties when used for metal processing.

- Experiments with applying $1.25 \mathrm{~mm}$ Gaussian and pedestal laser beams to a circular section wire mounted on a substrate showed radically different wetting properties. Clad tracks created with a pedestal beam were found to give successful wetting at a much lower power density than with a Gaussian beam, and also much less extreme mixing behaviour.

- Fresnel calculations show that absorption increases towards the outer part of the width, where the incidence angle increases. This increase has little effect on the Gaussian beam but enhances the effects of the pedestal beam, due its increased heat application in that region. The absorption profile is therefore dependent on both the incidence angle and on the applied irradiance profile, with greater dependence being placed on the irradiance profile.

- From the point of view of reflectivity, a round wire is equivalent to a flat surface across the majority of its width. Therefore the optimum tilt angle for wire feeding is approximately $70^{\circ}$

- The use of HOE's allows the optimisation of beam properties. The absorptive effects of changes in heat profile can be predicted by Fresnel calculations and then the same heat profiles can be reproduced by HOE's. This means that the optimal thermal profile for laser wire cladding can be predicted in advance theoretically, and then tested empirically, with the theoretical heat profile and the physical heat profile precisely matched to each other. 
- When the Gaussian beam diameter is increased, it is possible to create a clad track that is similar in shape to that created by a $1.25 \mathrm{~mm}$ pedestal beam. The major difference between them lies in their penetration.

- The reduction in penetration between a $3.5 \mathrm{~mm}$ Gaussian beam and a $1.25 \mathrm{~mm}$ pedestal beam has microstructural as well as dilution effects; resulting in greater dendritic growth and a larger average grain size

\section{References}

Boyden, S.B. \& Zhang, Y., 2006. Temperature and Wavelength-Dependent Spectral Absorptivities of Metallic Materials in the Infrared.pdf. Journal of Thermophysics and Heat Transfer, 20(1).

Capello, E., Colombo, D. \& Previtali, B., 2005. Repairing of sintered tools using laser cladding by wire. Journal of Materials Processing Technology, 164-165, pp.990-1000.

Gibson, M., 2012. The use of custom beam profiles in laser deposition. Loughborough University.

Hecht, E., 2002. Lasers and Laser Light. In Optics. Pearson Education, Inc., pp. 594-595.

Higginson, R.L. et al., 2012. Grain Size Control in the Weld Pool and Heat Affected Zone Using Holograms. In Materials Science Forum. pp. 430-345.

Higginson, R.L. et al., 2010. Weld Pool Shaping and Microstructural Control Using Novel Computer Generated Holographic Optic Laser Welding of Steel and Stainless Steel. Materials Science Forum, 638-642, pp.3673-3678.

Karlsson, B. \& Ribbing, C.G., 1982. Optical constants and spectral selectivity of stainless steel and its oxides. Journal of Applied Physics, 53(9), p.6340.

Kell, J. et al., 2011. Laser weld pool management through diffractive holographic optics. Materials Science and Technology, 28(3).

Kell, J., 2007. Melt Pool and Microstructure Manipulation Using Diffractive Holographic Elements in High Power Conduction Laser Welding. Loughborough University.

Kim, J.-D. \& Peng, Y., 2000. Plunging method for Nd:YAG laser cladding with wire feeding. Optics and Lasers in Engineering, 33(4), pp.299-309.

Liu, S. et al., 2014. Real-time monitoring of laser hot-wire cladding of Inconel 625. Optics \& Laser Technology, 62, pp.124-134. 
Mahmood, K., Stevens, N. \& Pinkerton, A.J., 2012. Laser surface modification using Inconel 617 machining swarf as coating material. Journal of Materials Processing Technology, 212(6), pp.1271-1280.

Mazumder, J. et al., 2000. Closed loop direct metal deposition: art to part. Optics and Lasers in Engineering, 34(4-6), pp.397-414.

Miranda, R.M. et al., 2008. Rapid prototyping with high power fiber lasers. Materials \& Design, 29(10), pp.2072-2075.

Modest, M.F., 2001. Reflectivity and Absorptivity of Opaque Surfaces. In J. F. Ready \& D. F. Farson, eds. LIA handbook of laser materials processing. pp. 175-181.

Mok, S.H. et al., 2008. Deposition of Ti-6Al-4V using a high power diode laser and wire, Part I: Investigation on the process characteristics. Surface and Coatings Technology, 202(16), pp.3933-3939.

Riveiro, a. et al., 2014. Laser cladding of aluminium on AISI 304 stainless steel with highpower diode lasers. Surface and Coatings Technology, 253, pp.214-220.

Shang, S. et al., 2014. Laser beam profile modulation for microstructure control in laser cladding of an NiCrBSi alloy. Surface and Coatings Technology, 248, pp.46-53.

Syed, W.U.H., Pinkerton, A.J. \& Li, L., 2005. A comparative study of wire feeding and powder feeding in direct diode laser deposition for rapid prototyping. Applied Surface Science, 247(1-4), pp.268-276.

Syed, W.U.H., Pinkerton, A.J. \& Li, L., 2006. Combining wire and coaxial powder feeding in laser direct metal deposition for rapid prototyping. Applied Surface Science, 252(13), pp.4803-4808.

Toyserkani, E., Khajepour, A. \& Corbin, S., 2005. Laser Cladding, CRC Press LLC.

Tyrer, J.R. \& Noden, S.C., 1996. Diffractive optical elements for manipulation of high power CO2 laser radiation - a feasibility study. , 2789.

Vilar, R., 1999. Laser cladding. Journal of Laser Applications, 11(2), p.64.

\section{Figure captions}

Figure 22: (a) Diagram of HOE beam path (b) Photograph of HOE optic (c) High-magnification SEM image of the HOE surface (Gibson 2012)

Figure 23: (a) Schematic of HOE operating principle (b) Resultant complex customised beam (Kell 2007)

Figure 24: Laser burn prints in perspex of (a) Gaussian beam profile (b) Pedestal beam profile (c) Rugby posts beam profile. Burn prints used with permission (Kell 2007) 
Figure 25: Schematic of applied power distribution when applying (a) $1.25 \mathrm{~mm}$ Gaussian beam and (b) larger Gaussian beam

Figure 26: Schematic of heating time profiles for (a) enlarged Gaussian beam and (b) pedestal beam on diameter $1 \mathrm{~mm}$ wire

Figure 27: Sample plate with twelve individual sample coupons

Figure 28 : Sample mounting jig

Figure 29: Beam profiles for (a) $1.25 \mathrm{~mm} \mathrm{TEM}{ }_{00}$ Gaussian beam and (b) pedestal diffractive beam (c) $3.5 \mathrm{~mm} \mathrm{TEM}_{00}$ gaussian beam

Figure 30: Schematic of wetting angles ( $\theta$ ) showing (a) acute wetting angle, giving poor clad track (b) obtuse wetting angle, giving successful clad track

Figure 31: Schematic of dilution definition

Figure 32: Optical micrographs of clad tracks created with a $1.25 \mathrm{~mm}$ Gaussian beam on pre-placed $1 \mathrm{~mm}$ round wire at increasing power densities

Figure 33: Optical micrographs of clad tracks created with a $1.25 \mathrm{~mm}$ square pedestal beam on pre-placed $1 \mathrm{~mm}$ round wire at increasing power densities

Figure 34: Flow lines and central indentation for Gaussian and holographic clad tracks

Figure 35: Optical micrographs showing (a) clad track created with a $3.5 \mathrm{~mm}$ Gaussian beam and (b) a clad track created with a $1.25 \mathrm{~mm}$ pedestal beam. Both were etched with Schaftmeister's reagent and illuminated using Diffractive Interference Contrast.

Figure 36: Schematic of how incidence angle changes with centreline distance

Figure 37: Graph of incidence angle vs. centreline distance for circular cross-section wire

Figure 38: Graph of reflectivity vs. transverse distance from the centreline

Figure 39: Absorbed irradiance distributions for Gaussian and pedestal laser beam profiles with distance from the centre line

Figure 40: Graph of Reflectivity vs. Incidence angle for stainless steel illuminated with a 10.6 mm laser beam

\section{Table captions}

Table 6: Alloy composition of mild steel (weight \%)

Table 7: Alloy composition of AISI 316 stainless steel (weight \%)

Table 8: Wetting angles with power densities for Gaussian laser beam

Table 9: Wetting angles at various power densities for Pedestal laser beam 
Table 10: Index of refraction of AISI 304 stainless steel at $\lambda=10.6 \mu \mathrm{m}$ (Boyden \& Zhang 2006) 